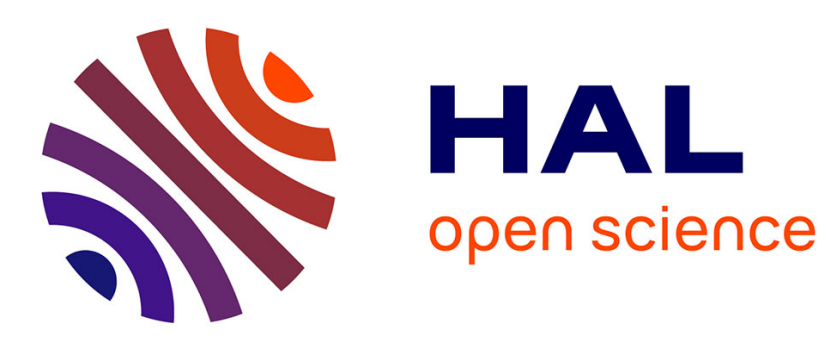

\title{
A re-entrant polymorphism N SA SC Nre
}

Nguyen Huu Tinh, F. Hardouin, C. Destrade, A.M. Levelut

\section{To cite this version:}

Nguyen Huu Tinh, F. Hardouin, C. Destrade, A.M. Levelut. A re-entrant polymorphism N SA SC Nre. Journal de Physique Lettres, 1982, 43 (2), pp.33-37. 10.1051/jphyslet:0198200430203300 • jpa00232004

\section{HAL Id: jpa-00232004 https://hal.science/jpa-00232004}

Submitted on 1 Jan 1982

HAL is a multi-disciplinary open access archive for the deposit and dissemination of scientific research documents, whether they are published or not. The documents may come from teaching and research institutions in France or abroad, or from public or private research centers.
L'archive ouverte pluridisciplinaire HAL, est destinée au dépôt et à la diffusion de documents scientifiques de niveau recherche, publiés ou non, émanant des établissements d'enseignement et de recherche français ou étrangers, des laboratoires publics ou privés. 
Classification

Physics Abstracts

$61.30 \mathrm{E}-64.70 \mathrm{E}$

\title{
A re-entrant polymorphism $\mathbf{N ~ S}_{A} S_{C} \mathbf{N}_{r e}$
}

\author{
Nguyen Huu Tinh, F. Hardouin, C. Destrade and A. M. Levelut (*) \\ Centre de Recherche Paul-Pascal, Domaine Universitaire, 33405 Talence Cedex, France \\ (*) Laboratoire de Physique des Solides, Bât. 510, 91405 Orsay, France \\ (Reçu le 15 octobre 1981, accepté le 19 novembre 1981)
}

\begin{abstract}
Résumé. - Le polymorphisme d'une nouvelle série : 4-[-4"-alkoxy-cinnamoyloxy] benzylidène-4'cyanoaniline a été étudié et la phase nématique rentrante a été observée pour les trois homologues $n=8,9,10$. Le composé $n=10$ présente la séquence $\mathrm{N} \mathrm{S}_{\mathrm{A}} \mathrm{S}_{\mathrm{C}} \mathrm{N}_{\mathrm{re}}$. Cette séquence inhabituelle est pour la première fois confirmée par les diagrammes de phase et par l'analyse des clichés de diffraction des Rayons X. La notion de $\mathrm{S}_{\mathrm{C}}$ partiellement bimoléculaire est introduite.
\end{abstract}

\begin{abstract}
The polymorphism of a new series 4-[-4"-alkoxy-cinnamoyloxy] benzylidene-4'-cyanoaniline was studied and a re-entrant nematic phase was observed for the three homologues $n=8,9,10$. The decyloxy compound exhibits the unusual $\mathrm{N} \mathrm{S}_{\mathrm{A}} \mathrm{S}_{\mathrm{C}} \mathrm{N}_{\mathrm{re}}$ sequence. For the first time, phase diagrams connected with $\mathrm{X}$-ray analysis confirm this result. The partial bilayer $\mathbf{S}_{\mathrm{C}}$ notion is introduced.
\end{abstract}

1. Introduction. - After the first observations of an enantiotropic re-entrant nematic phase at atmospheric pressure in pure compounds of the series : 4-alkoxy-benzoyloxy-4'-cyanostilbenes $[1,2,3]$, we have carried on the systematic study of series with three phenyl rings and a cyano end group. The general formula of these substances is the following [1-13] :

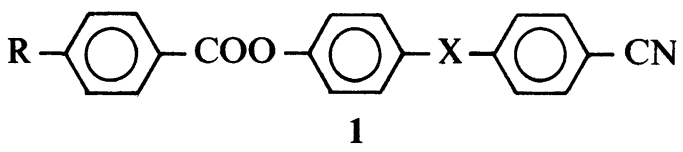

For $\mathrm{X}=-\mathrm{CH}=\mathrm{N}-$, Weissflog et al. [7] reported the novel $\mathrm{N} \mathrm{S}_{\mathrm{A}} \mathrm{S}_{\mathrm{C}} \mathrm{N}_{\mathrm{re}}$ sequence with the decyloxy compound. In this paper we present some homologues of a new series 4-[-4"-alkoxycinnamoyloxy] benzylidene-4'-cyanoaniline 2 which exhibit the same properties i.e. the occurrence of a $S_{C}$ phase between the $S_{A}$ phase and the re-entrant nematic phase :

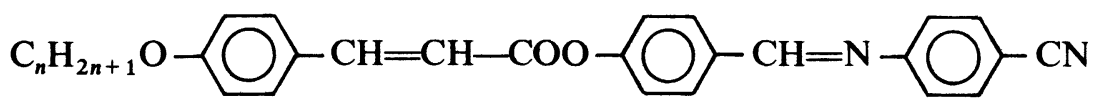

2

2. Results and discussion. - The substances were synthesized by the condensation of 4-formylphenyl 4'-alkoxycinnamates and 4-cyanoaniline in ethanolic solution. They were purified by recrystallization from ethanol. Phase transitions were studied both by polarizing microscopy (equipped with a Mettler F.P. 5 heating stage) and Differential Scanning Calorimetry (Dupont 990). The transition temperatures and types of mesophases are given in table I. 
Table I. - Transition temperatures $\left({ }^{\circ} \mathrm{C}\right)$ of compounds of the series $\mathbf{2}$

\begin{tabular}{|c|c|c|c|c|c|c|c|c|c|c|c|}
\hline$n$ & K & & $\mathrm{N}$ & & $\mathrm{S}_{\mathrm{C}}$ & & $\mathrm{S}_{\mathrm{A}}$ & & $\mathrm{N}$ & & I \\
\hline 6 & • & 120 & - & & - & & $\bullet$ & (92) & $\bullet$ & $>285$ & • \\
\hline 7 & • & 92 & - & & - & & • & 124 & $\bullet$ & $>285$ & $\bullet$ \\
\hline 8 & • & 99 & $\bullet$ & 152.5 & - & & • & 223 & $\bullet$ & 281 & • \\
\hline 9 & • & 93 & • & (74) & - & & • & 244 & $\bullet$ & 272 & • \\
\hline 10 & • & 100 & • & (70) & • & (87) & • & 257 & • & 267 & • \\
\hline 11 & • & 95 & - & & • & (66) & • & 260 & $\bullet$ & 264 & • \\
\hline
\end{tabular}

$\mathrm{K}$ : solid crystal; $\mathbf{S}_{\mathrm{A}}, \mathrm{S}_{\mathrm{C}}$ : smectic A, C;

$\mathbf{N}$ : nematic $; \mathrm{I}$ : isotropic; $\bullet$ : the phase exists;

- : the phase is not observed; ()$:$ monotropic transition.

As seen from table I, the $n=6,7$ homologues of 2 only show nematic $(\mathrm{N})$ and smectic $\mathrm{A}\left(\mathrm{S}_{\mathrm{A}}\right)$ phases. These $\mathrm{S}_{\mathrm{A}}$ phases give a McMillan parameter $\frac{T_{\mathrm{NA}}}{T_{\mathrm{NI}}} \approx 0.87\left(T_{\mathrm{NA}}\right.$ and $T_{\mathrm{NI}}$ are respectively the temperatures $(\mathrm{K})$ of the smectic A-nematic and the nematic-isotropic transitions) and they are probably similar to the low temperature $\mathrm{S}_{\mathrm{A}}$ phases of 1 with $\mathrm{X}=-\mathrm{CH}=\mathrm{CH}-$ [3]. Concerning the octyloxy derivative of 2 a stable re-entrant nematic phase with the $\mathrm{N}_{\mathrm{A}} \mathrm{N}$ sequence is ob-

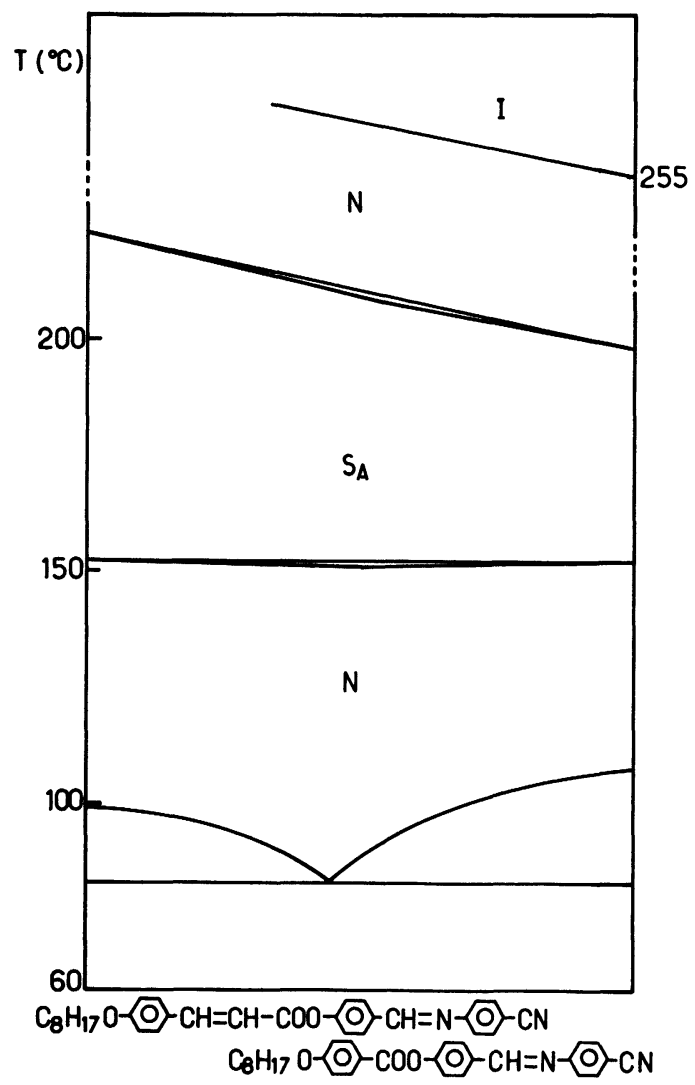

Fig. 1. - Diagram of the isobaric state for the mixture of $2(n=8)$ (on left) with $1\left(\mathrm{R}=\mathrm{C}_{8} \mathrm{H}_{17} \mathrm{O}\right.$, $\mathrm{X}=\mathrm{CH}=\mathrm{N}$ ) (on right). 
served. In contrast with the low homologues $\frac{T_{\mathrm{NA}}}{T_{\mathrm{NI}}}$ is hence larger than 0.87 , and this thermodynamical behaviour recalls the high temperature $S_{A}$ phase of the so-called « $T_{8} »[2-3]$ or similar compounds [4, 5, 9-12]. For the two following members of 2 a metastable re-entrant nematic phase exists. In addition, the decyloxy derivative exhibits an unexpected smectic $\mathrm{C}$ phase between the re-entrant nematic and the $\mathrm{S}_{\mathrm{A}}$, as reported by Weissflog et al. [7] in the series 1 with $\mathrm{X}=-\mathrm{CH}=\mathrm{N}-$. In the undecyloxy derivative the re-entrant nematic phase disappears while the monotropic $S_{C}$ phase is still revealed.

2.1 OptiCAL TEXTURE OBSERVATIONS. - On cooling the isotropic liquid of the decyloxy derivative, one can first observe the nematic phase with a classical thread-like texture. Below this nematic phase, the smectic A phase with a focal conic or homeotropic texture appears. On further cooling, the smectic $C$ phase becomes visible through a schlieren texture in the previous homeotropic domains and through a broken fan shaped texture in the other ones. On cooling the $S_{C}$ phase, the re-entrant nematic phase shows a schlieren texture or a paramorphic fan shaped texture.

2.2 IsOMORPHISM. - The identification of the polymorphism of the octyloxy derivative has been obtained by the miscibility method with the well known $\mathrm{N}-\mathrm{S}_{\mathrm{A}}-\mathrm{N}$ sequence of the octyloxy derivative of $\mathbf{1}(\mathrm{X}=-\mathrm{CH}=\mathrm{N}-$ ) [7, 8, 13] (Fig. 1). In comparing the decyloxy compound of 2 with equal alkoxy chain derivative of $1(X=-\mathrm{CH}=\mathrm{N}-)$ we give evidence for the perfect miscibility of the two smectic C phases (Fig. 2). In order to prove definitely these identifications X-ray investigations were performed using an equimolar mixture of the two decyloxy derivatives in which the $S_{C}$ phase is stable and the re-entrant nematic phase could exist till $50{ }^{\circ} \mathrm{C}$. With the purpose of observing the Bragg reflections on the layers we used a monochromatic $\mathrm{CuK}_{\alpha} \mathrm{X}$-ray beam perpendicular to a magnetic field $(0.3 \mathrm{~T})$. On cooling from the nematic phase we obtain

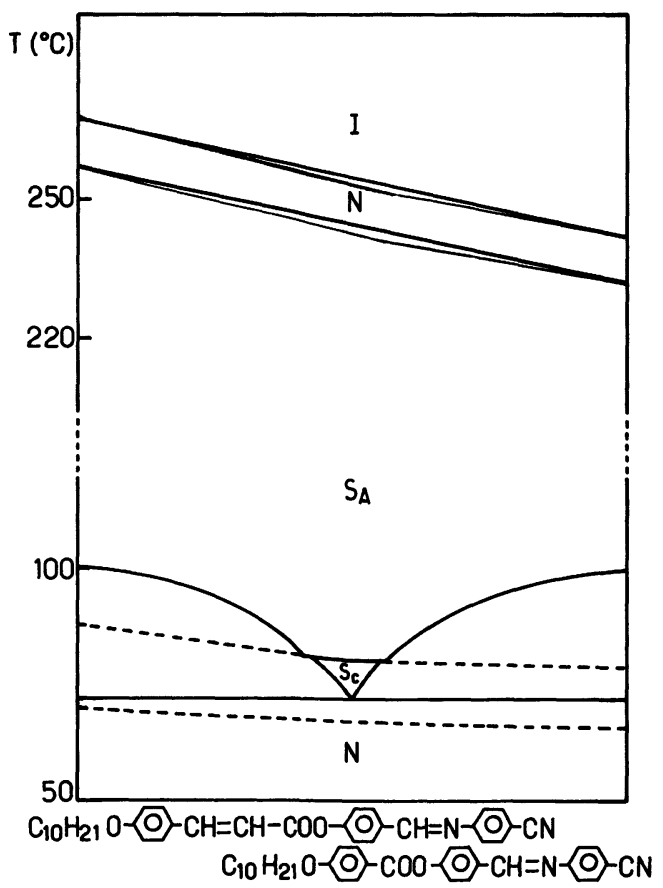

Fig. 2. - Diagram of the isobaric state for the mixture of $2(n=10)$ (on left) with $\mathbf{1}\left(\mathrm{R}=\mathrm{C}_{10} \mathrm{H}_{21} \mathrm{O}\right.$, $\mathrm{X}=-\mathrm{CH}=\mathrm{N}-$ ) (on right). The dashed lines correspond to monotropic transition temperatures $\mathrm{S}_{\mathrm{A}}-\mathrm{S}_{\mathrm{C}}$ and $\mathrm{S}_{\mathrm{C}}-\mathrm{N}_{\mathrm{re}}$. 
a $\mathrm{S}_{\mathrm{A}}$ single domain with a weak thermal dependence of the layer spacing $d$. The $d$ value is somewhat larger than the average molecular length $L_{\mathrm{M}}$ of the binary system : $d \sim 1.2 L_{\mathrm{M}}$. Thus this $S_{A}$ structure recalls the high temperature $S_{A}$ phase of the double re-entrant $N-S_{A}-N-S_{A}$ sequence $[14,15]$. Then, in the $S_{C}$ phase the smectic planes are rather disordered and the molecules are not quite aligned along the magnetic field direction. On the other hand, heating from the re-entrant nematic the molecules of the skewed cybotactic groups are of course parallel to the magnetic field and above the re-entrant nematic-smectic $\mathrm{C}$ transition (which is weakly first order $\Delta H_{\mathrm{N}_{\mathrm{re}}-\mathrm{s}_{\mathrm{C}}}<7$ cal.mole $\left.{ }^{-1}\right)$.

This alignment remains in $\mathrm{S}_{\mathrm{C}}$ with tilted layers : $d_{\mathbf{S}_{\mathbf{C}}} \rightarrow d_{\mathbf{S}_{\mathbf{A}}}$. Therefore we have been able to measure directly the tilt angle from the position of the small angles spots on diffraction patterns obtained by increasing temperature from the reentrant nematic phase. Close to the $S_{A}$ phase, the tilt angle $\alpha$ tends to zero and the layer spacing $d_{\mathrm{S}_{\mathrm{C}}}$ is hence much larger than the average molecular length $\left(d_{\mathrm{S}_{\mathrm{C}}} \rightarrow d_{\mathrm{S}_{\mathrm{A}}} \simeq 1.2 L_{\mathrm{M}}\right)$ (Fig. 3). This kind of $\mathrm{S}_{\mathrm{C}}$ is a partial bilayer $\mathrm{S}_{\mathrm{C}}$ similar to the $\mathrm{S}_{\mathrm{C}}$ phase studied by $G$. Pelz et al. [14] in a binary mixture. Moreover the $S_{C}-S_{A}$ transition appears like a continuous change of a partial bilayer biaxial medium in a uniaxial one $\left(\Delta H_{\mathrm{S}_{\mathrm{A}}-\mathrm{S}_{\mathrm{C}}}<5 \mathrm{cal}\right.$. mole $\left.{ }^{-1}\right)$.

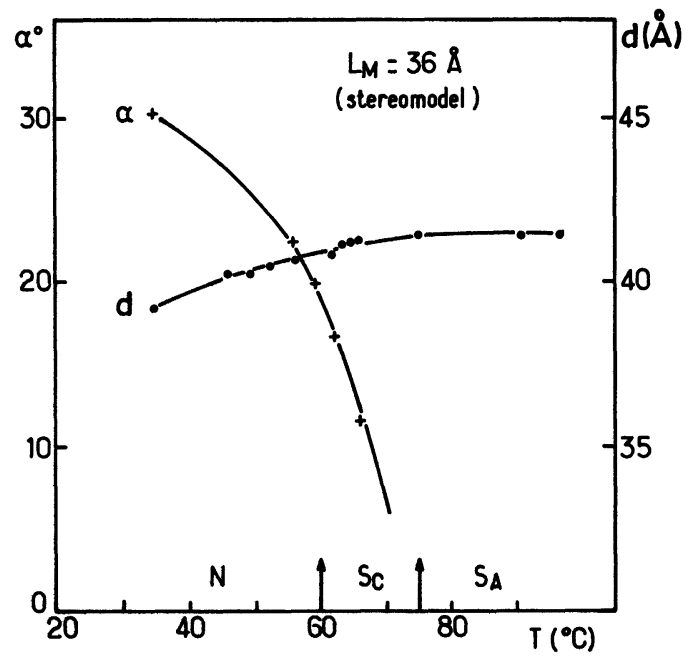

Fig. 3. - Layer spacing $d$ and tilt angle $\alpha$ versus temperature for an equimolar mixture of decyloxy compound of 2 with decyloxy derivative of $1(X=-\mathrm{CH}=\mathrm{N}-)$. In the re-entrant nematic phase these parameters are connected with the $\mathrm{S}_{\mathrm{C}}$ fluctuations.

At last, decreasing temperature in the re-entrant nematic phase, a second diffuse scattering slightly appears with a smaller wavelength than the one of the high temperature $S_{C}$ fluctuations (Fig. 4). This suggests a virtual low temperature smectic modulation $\left(S_{A}\right.$ or $S_{C}$ ?) at lower temperature and confirms that the re-entrant nematic phase originates from the competition between two kinds of damped smectic fluctuations $[15,17]$. 


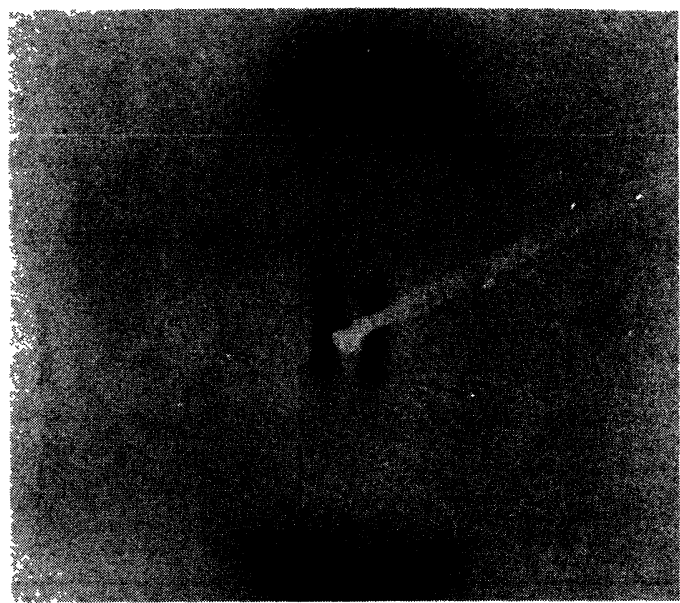

Fig. 4. - X-ray pattern of the re-entrant nematic phase at low temperature with skewed cybotactic groups and additional diffuse spots at larger angles.

\section{References}

[1] Hardouin, F., Sigaud, G., Achard, M. F., Gasparoux, H., Phys. Lett. 71A (1979) 317.

[2] Hardouin, F., Sigaud, G., Achard, M. F., Gasparoux, H., Solid State Commun 30 (1979) 265.

[3] Nguyen Huu Tinh, Sigaud, G., Achard, M. F., Gasparoux, H., Hardouin, F., Proceedings of the 3rd Liq. Cryst. Conf. of Socialist Countries, Hungarian Acad. Sci. (1979) (Pergamon Press, Akademiai Kiado, Budapest) 1 (1980) 147.

[4] Nguyen Huu Tinh, Gasparoux, H., Mol. Cryst. Liq. Cryst. Lett. 49 (1979) 287.

[5] Nguyen Huu Tinh, Pourrere, A., Destrade, C., Mol. Cryst. Liq. Cryst. 62 (1980) 125.

[6] Hardouin F., Levelut, A. M., Nguyen Huu Tinh, Sigaud, G., Mol. Cryst. Liq. Cryst. Lett. 56 (1979) 35.

[7] Weissflog, W., Pelz, G., Wiegeleben, A., Demus, D., Mol. Cryst. Liq. Cryst. Lett. 56 (1980) 295.

[8] Nguyen Huu Tinh, Zann, A., Dubois, J. C., Billard, J., Mol. Cryst. Liq. Cryst. Lett. 56 (1980) 323.

[9] Nguyen Huu Tinh, Joussot-Dubien, M., Destrade, C., Mol. Cryst. Liq. Cryst. Lett. 56 (1980) 257.

[10] Heppke, G., Hopf, R., Kohn, B., Praefke, K., 3rd Liq. Cryst. Conf. of Socialist countries, Hungary (1979).

[11] Shadashiva, B. K., Int. Liq. Cryst. Conf. Bangalore (1979).

[12] Nguyen HuU Tinh, Destrade, C., Nouv. J. Chimie 5 (1981) 337.

[13] Sigaud G., Nguyen Huu Tinh, Hardouin, F., Gasparoux, H., Mol. Cryst. Liq. Cryst. 69 (1981) 81.

[14] Pelz, G., Diele, S., Wiegeleben, A., Demus, D., Mol. Cryst. Liq. Cryst. Lett. 64 (1981) 163.

[15] Hardouin, F., Levelut, A. M., J. Physique 41 (1980) 41.

[16] Hardouin, F., Levelut, A. M., Sigaud, G., J. Physique 42 (1981) 71.

[17] Prost, J., Springer series in Chemical Phys. (Springer, Berlin, Heidelberg, New York) 1980, p. 125. 